\title{
3D INTERPRETATION AND FUSION OF MULTIDISCIPLINARY DATA FOR HERITAGE SCIENCE: A REVIEW
}

\author{
E. Adamopoulos ${ }^{1}$, F. Rinaudo ${ }^{2}$ \\ ${ }^{1}$ Department of Computer Science, Università degli Studi di Torino, Corso Svizzera 185, Torino, Italia \\ ${ }^{2}$ Department of Architecture and Design, Politecnico di Torino, Viale Mattioli 39, Torino, Italia \\ efstathios.adamopoulos@unito.it, fulvio.rinaudo@polito.it
}

Commission II, WG II/8

KEY WORDS: heritage, data interpretation, modelling, multi-sensor, multi-spectral, data fusion

\begin{abstract}
:
Activities related to the protection of tangible heritage require extensive multidisciplinary documentation. The various raw data that occur have been oftentimes been processed, visualized and evaluated separately leading to aggregations of unassociated information of varying data types. In the direction of adopting complete approaches towards more effective decision making, the interpretation and fusion of these data in three dimensions, inserting topological information is deemed necessary. The present study addresses the achieved level of three-dimensional interpretation and fusion with geometric models of data originating from different fields, by providing an extensive review of the relevant literature. Additionally, it briefly discusses perspectives on techniques that could potentially be integrated with point clouds or models.
\end{abstract}

\section{INTRODUCTION}

The necessity of tangible heritage documentation and analysis, has been emphasized multiple times through the international agreements and conventions, including the Lausanne Charter (ICOMOS, 1990) and the Krakow Charter (ICOMOS, 2000). Additionally, the collection and exploitation of information of different disciplines has been underlined as a means to effectively interpret heritage objects and to plan the preservation and conservation treatments, as mentioned in Letellier et al. (2015). As discussed in Kioussi et al. (2012), the recording of cultural heritage objects should be thorough, multiscale and cover a wide scope of information, so that it can assist inspection, diagnosis, intervention studies, pilot and final intervention works, as well as assessment and monitoring processes. The multidisciplinary recording and analysis of tangible heritage usually refers to archaeological, architectural, morphological and structural surveys, investigation procedures concerning building materials, decay, past interventions and state of conservation (Moropoulou et al., 2003). That translates to the collection of metric, scanning, spectral, chemical, geophysical, constructional and climatic data (Adamopoulos et al., 2017 and Georgopoulos et al., 2017).

Faults of the past regarding fragmentary approaches, and aggregation of big data about heritage not integrated which led to incompatible interventions, have resulted to a realization that holistic, interdisciplinary, continuous documentation, enables an accurate decision-making concerning built heritage protection. These experiences led to understand that the greater the level of integration of heritage data, the more useful are the results. As presented in Bastonero et al. (2014) and Ramos \& Remondino (2015) data fusion in cultural heritage can be performed at different levels. This paper gives an overview of the different fusion approaches adopted in the heritage science field to model data from different techniques and specifically Laser Scanning, InfraRed-Thermography (IRT), Spectral and Multi-Spectral Imaging, Ultrasonic Testing (UT), Ground Penetrating Radar (GPR), X-Ray Radiography and Computed Tomography in combination with geometric data or relevant three-dimensional approaches that have been developed to interpret them, since those originating from non-imaging fields have very rarely been fused with 3D models produced by using 3D point clouds offered by sensing techniques aiming to $3 \mathrm{D}$ geometry.

\section{LASER SCANNING}

Terrestrial lasers scanners (TLSs) utilize electro-magnetic waves to measure distances, usually at the infrared range (wavelength ranging from $1 \mathrm{~mm}$ to $700 \mathrm{~nm}$ ). These sensors are not only useful for the rapid three-dimensional recording of large volumes of geometric data, but also collect reflectance intensity information that depend on the characteristics of materials. As the attribution of raw intensity data is point based and takes place during data acquisition, no further fusion techniques are usually needed. Although, as demonstrated in Li and Cheng (2018) the correction of TLS intensity data with data-driven models is a necessary step for close range applications before data interpretation. Then TLS intensity data can be visualized as scales of grey or pseudo colours on point cloud vertices, mesh faces -using any common texturing algorithm- or on ortho-image pixels. Since different building materials and deterioration products present different radiometric properties, intensity data can be exploited to obtain classification results, that otherwise would be achieved through time and cost-consuming manual inspection and analyses.

Armesto-González et al. (2010) performed unsupervised classification on orthoimages with intensity data from a terrestrial laser scanner (TLS) to identify weathering on stone walls at the ruins of the Santo Domingo, located in the heart of the city of Pontevedra, Galicia (Spain). García-Talegón et al. (2015) evaluated the unsupervised classification of intensity orthoimages of Villamayor Stone in Salamanca (Spain) and were able to identify pathologies such as humidity and biodeterioration, assess the total surface affected by rock damage and measure the rock surface involved in scaling and fissuring. Additionally, Riveiro et al. (2016) used intensity orthoimages produced from LIDAR data for automatic morphologic analysis-geometric segmentation of Quasi-Periodic masonry walls in Guimarães (Portugal). For accurate studies of the materials and deterioration, raw intensity information can be converted to surface reflectivity data through radiometric calibration of the instrumentation to enable quantitative and qualitative multitemporal assessment. Radiometric calibration depends on scanning geometry, material 
surface properties and specifics of the instrumentation. Lerones et al., (2016) used corrected reflectivity data from TLS to produce textured partial models of the Cathedral of Ciudad Rodrigo, at the province of Salamanca (Spain) to detect moisture. Li and Cheng (2018) utilized point clouds with reflectivity data to assess damage on historic Chinese structures. Furthermore, SánchezAparicio et al. (2018) used models and extracted orthoimages with reflectance values -after radiometric calibration of TLS- to map moisture, salt crusts and biological colonization on the San Francisco Master Gate of the Almeida Fortress (Portugal).

\section{INFRARED THERMOGRAPHY}

Thermography is an imaging technique of the infrared range with thermographic cameras usually being able to detect radiation of $9 \mu \mathrm{m}-14 \mu \mathrm{m}$. In heritage science IRT is usually associated with assessment of the state of preservation of historic structures to identify pathologies related to moisture. A defect in this method is that it is affected by environmental factors and thus specialized calibration is required to acquire accurate results. Additionally, compared to consumer-level digital cameras, thermal cameras have significantly lower resolutions commonly ranging from 160 x 120 to $640 \times 480$ pixels. Thus, sensing and interpretation of thermal characteristics of historic structures requires collection of large numbers of thermal images (Cho et al., 2015). Since the manual analysis of these large datasets is very difficult, thermal modelling has often been explored as a more complete means for thermographic inspection which additionally provides invaluable geometric information for the damaged areas.

A simple method that allows the performance of geometric and thermal measurements at the same product simultaneously is photogrammetric image rectification which requires calibration of the thermal camera (Laguiela et al., 2016). A common method of thermal modeling is the separate reconstruction of the geometry through laser scanning or photogrammetry and then the fusion with thermal data with a manual D2-to-3D registration. Some of the earliest examples of fusing geometric and thermal information for heritage purposes include Rizzi et al. (2007) and Cabrelles et al. (2009) who both used corresponding points coordinates to estimate the orientation of thermograms for Palazzo Barbieri in Verona, Italy and for a tomb in Petra, Jordan respectively. The thermal images where then used to texture photogrammetric models. Costanzo et al. (2015) also used corresponding point coordinates to calculate external orientation parameters of individual thermograms. Thermograms where then used to texture parts of models created with TLS for historical buildings in Cosenza, Italy. The resulting model and the extracted orthoimages were used to identify cracks, detachments and zones of moisture. Brumana et al. (2013) performed a combined bundle adjustment of optical and thermal image datasets, using some manually selected common tie points, to obtain better estimations of the external parameters for the thermal images. Thermal images textured the reconstructed geometry to facilitate the archaeological observations.

Another approach for thermal modelling refers to platforms with multiple sensors whose relative positions have been calibrated. Alba et al. (2011) set up bi-camera systems with optical and thermal cameras. By knowing the orientations of the optical cameras -after constructing point clouds for heritage buildingsand the relative orientation of the different cameras, were then able to texture point clouds with thermal data. Borrmann et al. (2013) developed a robotic system equipped with laser scanner, webcam and thermal camera that simultaneously collected geometric, optical and thermal information and through a calibration algorithm could automatically determine the relations between the sensors, to directly color the acquired point clouds of facades with texture. Merchán et al. (2018) created a bi-camera system consisting of TLS, optical and thermal camera calibrated in order to obtain the geometric relationships between them. By associating the pixels of the thermal image to the single points through a projective transformation matrix were able to assign temperature values to the point cloud. Therefore, they were able to produce a thermal point cloud for the Baritel de San Carlos in Almadenejos, Spain.

Recently, cloud-to-cloud and model-to-model registration options have also been explored. Lin et al. (2018) co-registered separate point clouds of building facades created from optical and thermal images to acquire the orientation parameters of thermal image acquisition calculated by back projection. Then textured the model generated from the point cloud through commercial software. Hoegner and Stilla (2018) explored three methods for model and point cloud-based matching to improve the orientation parameters of thermal images and therefore calculate their projection into the models. The first method matched a relative point cloud to the model of a building using GNSS data of the camera track. The distance between them was adjusted with a least-squares adjustment. The second method induced an existing model into the camera orientations to extract a point cloud directly from the images. The third method produced a point cloud from the images including the orientations of the aerial platform used and co-registered it to a point cloud from the optical images. In all cases, a thermal image mosaic was generated to texture the model of facades.

Finally, automated or semi-automated photogrammetric software implementing Structure from Motion (SfM) and Multiview Stereo (MVS) algorithms which is becoming extremely popular for heritage applications has been recently explored for thermal modeling. Erenoglu et al. (2017) provides one example of the use of commercial SfM MVS software to produce a thermal model of Assis Ancient theater in Behramkale, West Turkey, directly from thermograms captured with a low-resolution thermal camera mounted on a UAS platform.

\section{SPECTRAL AND MULTI-SPECTRAL IMAGING}

Multispectral imaging is a form of non-invasive imagery. Based on the detection of reflected or emitted electromagnetic radiation with wavelengths ranging between $10 \mathrm{~nm}-1 \mathrm{~mm}$, this technique has been used extensively for archaeological prospections (Verhoeven, 2018), characterization of historic materials and pathologies (Del Pozo et al., 2016). As in the case of infrared thermo-cameras, multispectral cameras are usually of lower resolutions than those of consumer-level digital cameras, although substantially higher then thermal ones. The approaches explored for multi-spectral modeling of heritage include simple 2D-to-3D registration with common points between the geometric model produced by photogrammetric or scanning workflows, as performed in Kadzierski et al. (2017) for heritage buildings and more complicated solutions. Brusco et al. (2006) developed a system for automatic multispectral modeling of historic architecture by integrating a range camera and an image spectrograph. The automatic implemented procedure included: automatic detection of a common region between overlapping textured 3D views, pairwise registration of 3D views, global registration, multi-spectral texture construction and surface fusion. Simon et al. (2012) and Chane et al. (2013) applied photogrammetric tracking on pre-calibrated multispectral cameras and fringe projection systems for 3D digitization used on the same scenes, to co-register and project the multi-spectral data on 3D models of heritage surfaces, with accuracy better than half an image pixel. Pelagotti et al. (2009) and Remondino et al. (2009) extracted depth maps from 3D heritage models, whose pixels maintained correspondence with the vertices of the respective $3 \mathrm{D}$ models, to register those maps with texture from 
multispectral images through Maximization of Mutual Information algorithms. Commercial automated or semiautomated photogrammetric software which utilizes SfM algorithms has also been recently explored for heritage multispectral modeling, as in the works of Grifoni et al. (2017) for triplets of images at different wavelengths, Grifoni et al. (2018) for larger datasets and Nocerino et al. (2018) for visible spectrum and Ultraviolet Luminescence images of a vase. The availability of digital cameras modified for UV, IR and multispectral imaging has further widened the application of this type of photogrammetric software, since higher resolutions become available that facilitate the common feature detection at the first step of shape reconstruction. Two examples are provided by Georgopoulos et al. (2016), who performed large scale mapping of an archaeological excavation site using datasets of images acquired with a camera optimized for near infrared imaging mounted on an unmanned aerial platform with two commercial photogrammetric software and Webb et al. (2018), who also used a near infrared modified camera and commercial SfM photogrammetric software to model a mango wooden vase. Another workflow that produces models of metric quality with spectral information includes separate orientation of the optical and nonoptical images acquired for the same scene, so that the final 3D surface can be produced more precisely by the optical images and then texturized accordingly using the non-optical images.

\section{GROUND-PENETRATING RADAR}

GPR methods consist non-destructive geophysical prospection techniques utilizing waves with frequencies between $10 \mathrm{MHz}-2.5$ $\mathrm{GHz}$. The method is based on the transmission of electromagnetic pulses into the ground or into a structure and the recording of the signal that is reflected to the surface and carries information about the position of underlying media with different dielectric properties (Perez-Gracia et al., 2009). In the field of cultural heritage GPR is increasingly used for archaeological prospection (Lechebusch, 2003), the investigation of the inner structure of columns, buttresses and walls (Perez-Gracia et al., 2013), the diagnosis of damaged zones (Binda et al., 2000) and the locating of moisture (Barone and Ferrara, 2018). The most common reflection acquisition methodology is single-offset, because it is the simplest and fastest way to collect data, by moving two antennas with constant distance between the transmitter and the receiver to produce $2 \mathrm{D}$ sections. In many GPR surveys, usually in archaeological prospection, this Common Offset procedure is repeated at regular intervals and for several survey lines, which are usually located parallel to one other. Using three-dimensional Common Offset, more realistic representations of underground space are provided, which allows not only the location, but also for reconstruction of buried structures. These 2.5D approaches (or time-slices) provide accurate and intuitive display of the underground distribution, and adequate spatial correlation between reflectors in varying depths. They can be further processed to calculate $3 \mathrm{D}$ volumes.

One of the main challenges of this technique is the interpretation of the collected data, that depends on the quality of the raw measurements and the knowledge of the inspected materials with the corresponding dielectric properties. To produce a satisfactory interpretation, the methods of data acquisition and processing are therefore crucial (Martinho and Dionísio, 2014). As can be seen from the examples set forth below, several published studies in this direction, over the last decade, showcased many different techniques for the acquisition and processing of GPR data to achieve better interpretations in three-dimensional space. Trinks et al. (2017) collected measurements along parallel survey lines with $25 \mathrm{~cm}$ cross-line spacing and processed them into multiple GPR depth slices to map the remains of Bronze-Age settlements.
Following the same technique, Gaffney et al. (2004) used timeslices to study a Roman Forum in the Middle Tiber valley north of Rome, Yalçiner et al. (2009) used time-slices to study an archaeological site of Nysa in the valley of Büyük Menderes River south-east of İzmir and Zhao et al. (2013) to conduct the archaeological prospection of a part of the Aquileia Park in North-West Italy. Nuzzo et al. (2002), Perez-Gracia et al. (2009) and Kadioglu et al. (2010) further interpreted the results to produce 3D volumes from same amplitude data deriving from the GPR surveys to investigate large archaeological sites in Lecce, Italy and in Ankara, Turkey respectively. Furthermore, Leucci et al. (2011) and Santos-Assunçao et al. (2014) also produced 3D volumes from iso-amplitude data to assess internal damages, inner pipes and void areas in columns. Ferrara and Barone (2015) crated a pseudo 3D-reconstruction of moisture inside a heritage building by extracting an iso-surface from the time-slices. The only paradigm of 3D fusion of GPR data with heritage models until this research, comes from Agrafiotis et al. (2017), who used the georeferenced sections from the GPR data of the internal structure of the Tomb of Christ within the Church of the Holy Sepulchre in Jerusalem, as contours to produce a 3D surface model, which was merged with the 3D model of the interior and the exterior of the structure, thus creating a complete model of the stratigraphy of the historical phases.

\section{ULTRASONIC TESTING}

UT methods refer to non-destructive prospection techniques utilizing waves with frequencies higher than $20 \mathrm{kHz}$. These techniques are similar to acoustic and electromagnetic methods, but they can be used for larger scale applications and produce higher resolution results. Shorter wavelengths translate to higher resolutions, meaning that smaller targets can then be detected accurately. UT is based on the transmission, reflection and recording of ultrasonic waves. The emitted energy propagates through the medium and scattered energy is detected by a transducer. The records are interpreted in images of the inner medium which include changes in the elastic parameters (Marecos et al., 2016). UT can be used for the calculation of the thickness of crusts or other weathering layers and of the depth of cracks developed in building materials, evaluation of internal damage and decay, assessment of mechanical characteristics, the quality and the homogeneity of components and the location of reinforcements (Martinho and Dionísio, 2014). Ultrasonic testing is not a newly introduced method for non-destructive testing of tangible heritage as it has been applied in a plethora of case studies on structures (Calia et al., 2012, Mesquita et al., 2018 \& Moropoulou and Labropoulos, 2015) and sculptures (Pamplona et al., 2012). Bagnéris et al. (2017) were able to carry out a threedimensional representation of the individual ultrasound velocity measurements inside an imperial marble statue of Alba-laRomaine (France), by relying on a 3D model that included small numbered stickers on the marble surface, which materialized the positions of the emitter and receiver for each measurement UT images consist of pixels representing finite, discrete, small areas of the heritage object and are associated with values of intensity. Calculations carried out for each pixel allow a quantitative description of physical characteristics, such as the velocity of wave propagation. The number of pixels can be changed, so that the effect of spatial resolution on the quality of the image can be studied. Ultrasound tomography images acquired through a dense configuration of transmitters and receivers, attributed with different heights have been used by Zielińska and Rucka (2018) to assess the three-dimensional internal structure of various masonry pillars. Similarly, the internal conditions of building stone materials of the investigated architectural elements were represented in a 3D view of 
intersecting tomographic slices by Fais et al. (2018) for the Palazzo di Città building in the historical centre of Cagliari. Additionally, tomographic images were superimposed on visual geolocated orthoimages and decay maps by Fais et al. (2017) to correlate historic materials and degradation processes.

The geolocated or spatially correlated ultrasound tomographic images and ultrasonic velocity measurements can be converted in $3 \mathrm{D}$ volumes through specialized software as in the cases of Fais et al. (2018) that was mentioned before, Leucci (2017) for the depiction of the internal state of conservation of historic masonries subjected to weathering and Martinho et al. (2017) for the representation of the conservation state of limestone blocks affected by fire. 3D tomographic results produced by GeoTom CG software were superimposed over 3D topographic models in Capizzi et al. (2013) for the Eleonora d'Aragona statue and in Sambuelli et al. (2015) for two sculptures of the Egyptian museum of Turin, to better visualize weak volumes and changes in elasticity attributes. Conclusively, Di Pietra et al. (2017) performed a high-level integration of textured meshes, extracted from point clouds classified according to transmission velocities of ultrasonic waves inside an Egyptian sculpture at the archaeological museum of Bologna, aiming to enhance the final graphical representation of the tomographic results and to subject the data regarding conservation state to quantitative analysis.

\section{X-RAY RADIOGRAPHY AND COMPUTED TOMOGRAPHY}

$\mathrm{XRR}$ is a non-destructive investigative technique, originating from the medical sector. It involves beams of radiation with wavelengths ranging from $0.01 \mathrm{~nm}-10 \mathrm{~nm}$ emitted by a source of electromagnetic radiation, that are partially absorbed by an object depending on density and compositional characteristics and captured by detectors behind the object to create two dimensional images. It is a fast and cost-effective technique which enables to capture cross-layer views of objects obscured under corrosion layers or burial accretions without intervention. XRR was the first technique that allowed to obtain information about subsurface structures and is thus used extensively for the study of metalwork (Mannes et al., 2015 and Fell et al., 2016), wooden sculptures (Hersak et al., 2013), paintings (Lo Giudice et al., 2017) and textiles (O'Connor and Brooks, 2007). However, regarding the three-dimensional perspective of the technique, the information depicted in every pixel of a radiograph image represent absorption data collected of an x-ray cone, that is emitted from the radiation source at one side of the object and is recorded from the detector at the other side, includes data for all intersecting internal surfaces of the object and not only the external surfaces and thus, result in a digital product that cannot be treated as a central or an ortho-projection of intensity data. That means that the radiography cannot be projected to a point cloud or model of an object without significant errors resulting from the 'projection' and cross-sectional information included, especially when the object has great depth variations. Thus, the integration of $x$-ray imaging products could only be integrated with models of relatively thin and planar objects, to not create any misconceptions referring to the type and geometry of data acquired through this technique. Furthermore, the results of XRR are affected by chemical nature, thickness and density of the object under study and therefore objects of substantially high density, as for example objects, made completely of rock or metal, more than a few $\mathrm{cm}$ thick, cannot be investigated because of the depth that this type of radiation can penetrate. In these cases, instrumentation of higher radiation intensity needs to be used in large facilities.

$\mathrm{CT}$ is also a powerful non-invasive and non-destructive X-Ray technique, yet allows the full volume visualization of an object, giving away morphological and physical information. The data acquired from CT in the raw form consist of a list of voxels with known coordinates in a three-dimensional axis system and the respective $\mathrm{x}$-ray absorption values. The dimensions of the voxels represent the resolution of the acquisition process, with a range that can vary from a few microns to some millimeters. The data can be translated in 2D cross-sections or a 3D cloud and software has been developed for the visualization but not the management of the point clouds. The acquisition and post processing are relatively fast, so that for a small object it would take less than a day to produce results with a resolution around $1 \mathrm{~mm}$. The main drawback of CT much like XRR remains; the objects under study should be movable and of relatively small dimensions. Although, during the last years instrumentation has been developed to accommodate the tomography of large paintings, sculptures of human dimensions and archaeological findings of big volumes. Re et al. (2014) used such CT instrumentation on a large cabinet made by Pietro Piffeti of rare wood, polychrome ivories, nacre and tortoiseshell to find building techniques, state of preservation and previous interventions. Re et al. (2015) performed CT on a soil block with archaeological interest to assess the state of conservation of a fragmented metal belt, in order not to be destructed during micro-excavation and to recreate its shape after cleaning. More specifically, segmentation of the produced point cloud was performed to separate virtually the finding from the containing soil. Re et al. (2016) used CT to study the cover of an ancient Egyptian coffin. Peccenini et al. (2014) also executed CT using modified equipment to $3 \mathrm{D}$ reconstruct the volume and the inner structure of a contemporary art wooden sculpture. Morigi et al. (2007) and Morigi et al. (2010) used a transportable X-ray $\mathrm{CT}$ system to create $3 \mathrm{D}$ reconstructions and virtual slices for an ancient wooden globe and for two wooden Japanese sculptures $\left(13^{\text {th }}\right.$ and $18^{\text {th }}$ century) respectively. Additionally, Zhang et al. (2012) used synchrotron radiation CT facilities to perform a detailed 3D reconstruction of a Boxwood prayer nut depicting the crucifixion of Christ, to virtually segment its model through open source software and 3D print it to construct a physical copy, which can be manipulated and examined, without any risk of damage to the original. Finally, Pitzalis et al. (2008) performed a high-level fusion of data produced with Photogrammetry, $\mu$ topography and X-ray CT to produce a complete $3 \mathrm{D}$ model of the Cylinder seal of Ibni-Sharrum from the Agade period to minimize noise throughout the whole surface.

\section{CONCLUSIONS AND FUTURE PERSPECTIVES}

This paper has provided a comprehensive review on the different methodologies used for 3D interpretation of multisensory data used for heritage science purposes. All mentioned techniques are non-invasive and non-destructive and therefore are deemed optimal for cases of small, fragile or high value historic materials. Additionally, the relevant instrumentation is portable for all the above-mentioned techniques and can be used for in-situ studies, except for the XRR and CT which can only be transportable from one laboratory to another.

As discussed here, the imaging related techniques can easily produce point clouds or models with texture useful for recording or diagnostic reasons. On the other hand, techniques based on electromagnetic waves far from the optical spectrum can usually provide information about the internal characteristics of materials and cannot be easily translated to shapes or need to be further fused with geometric information deriving from other techniques to acquire some topological validity. Even for imaging data of Ultra-Violet and Infra-Red spectra, 3D interpretation approaches have been concentrated more around $2 \mathrm{D}$ image to $3 \mathrm{D}$ registration and more recently model-to-model or cloud-to-cloud registration. These approaches aim to maintain the level of geometric detail 
provided by reconstructions from scanning or visible spectrum photogrammetry and texturize them with the different spectral imaging data. Thus, it should be highlighted that most problems regarding interpretation of heritage information from different sensors are a matter of resolution. Although, some contemporary SfM commercial photogrammetric software have given adequate results for heritage applications concerning the shape reconstruction from images out of visible spectrum, especially for images collected with converted cameras -modified to be sensitive for small areas out of the optical range- which are becoming increasingly popular duo to their low cost and high resolution, comparing to spectral and multispectral sensors used usually for the inspection of materials.

Only a very few mentions of the integration of more than one of the interpretational approaches described here can be found in literature concerning heritage science, as in the application of Sambuelli et al. (2011) where a 3D rendering of UT maps and GPR trace envelope is presented (Figure 1). The fusion of more than one three-dimensional interpretation of sensor data from techniques coming from different fields is very important for the complete documentation, recording and assessment of the state of preservation for tangible heritage, as already stated and is therefore a critical direction for future research.

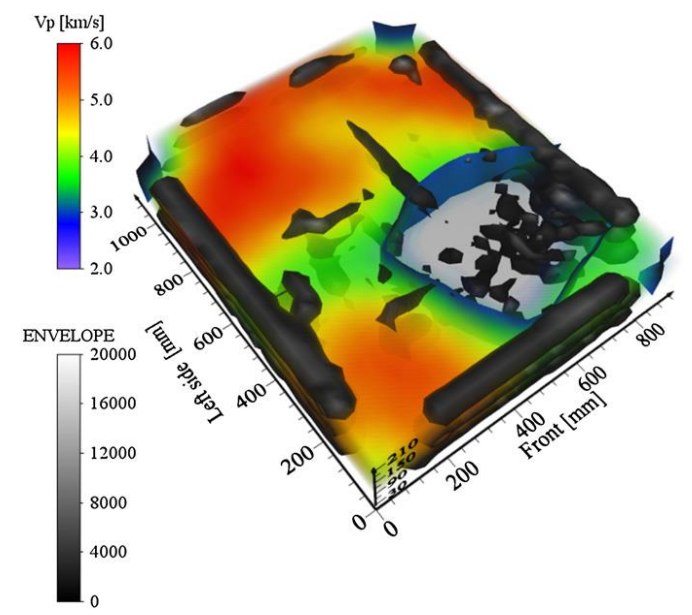

Figure 1: Combined 3D rendering of UT and GPR data (Sambuelli et al., 2010)

It should be briefly mentioned that the elemental mapping of surfaces through scanning spectroscopic techniques as MAcro XRay Fluorescence (MA-XRF), can potentially be interpreted in a three-dimensional way, since the produced data are of imagery types and most of the instrumentation developed provide data for the distances between the mapped surfaces and the movable detecting sensor, which if translated to a data elevation model could be potentially co-registered with the model of the surface to texturize it with the elemental maps. This consists a topic that the authors want to address in future research. MA-XRF elemental mapping has successfully been implemented for the study of paintings (Alberti et al. 2017, Amato et al. 2018, Caliri. 2017) and frescoes (Sccaroni et al. 2018).

3D metric survey does not mean just the modelling of visible surfaces but a real 3D model set-up by considering the aim of the survey itself. The integration of the above described inspection techniques, that allow a 3D characterization of the investigated objects, opens new perspective in the $3 \mathrm{D}$ model setting-up to correctly represent the volumetric elements which can host the thematic information coming from the different acquired information. The knowledge of the characteristics of the needed 3D model elementary parts could influence the metric data acquisition both in terms of resolution and accuracy, therefore ad-hoc investigations have to be performed to optimize the point cloud acquisition in order to achieve the needed accuracy and resolution in the different part of the investigated object. The possible 3D integration of the thematic information will allow also the comparison of the possible analysis performed to ease the cross interpretation. This is the main topic of the research that the authors would like to point out in the next years by collaborating with specialists in the fields of the different inspection techniques.

\section{ACKNOWLEDGEMENTS}

The research leading to this paper was conducted in the context of the Tech4Culture PhD programme at the University of Turin, which receives funding from the European Union's Horizon 2020 Research \& Innovation programme under the Marie SkłodowskaCurie grant agreement No. 754511 (H2020-MSCA-COFUND) and from the Compania di San Paolo.

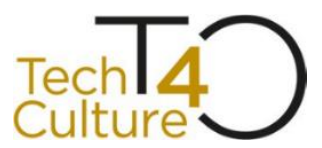

UNIVERSITÀ DEGLI STUDI DI TORINO
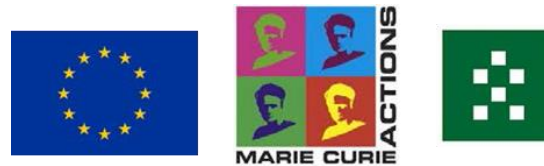

Compagnia di San Paolo

\section{REFERENCES}

Adamopoulos, E., Tsilimantou, E., Keramidas, V., Apostolopoulou, M., Karoglou, M., Tapinaki, S., Ioannidis C., Georgopoulos A. \& Moropoulou, A. 2017. Multi-sensor documentation of metric and qualitative information of historic stone structures. In ISPRS Annals of Photogrammetry, Remote Sensing and Spatial Information Sciences, IV-2/W2, 1-8.

Agrafiotis, P., Lampropoulos, K., Georgopoulos, A. and Moropoulou, A., 2017. 3D Modelling the Invisible using Ground Penetrating Radar. International Archives of Photogrammetry, Remote Sensing and Spatial Information Sciences, 42, 33-37.

Alba, M.I., Barazzetti, L., Scaioni, M., Rosina, E. and Previtali, M., 2011. Mapping infrared data on terrestrial laser scanning 3D models of buildings. Remote Sensing, 3(9), 1847-1870.

Alberti, R., Frizzi, T., Bombelli, L., Gironda, M., Aresi, N., Rosi, F., ... \& Cartechini, L. (2017). CRONO: a fast and reconfigurable macro X-ray fluorescence scanner for in-situ investigations of polychrome surfaces. X-Ray Spectrometry, 46(5), 297-302.

Amato, S. R., Burnstock, A., Cross, M., Janssens, K., Rosi, F., Cartechini, L., Fontana, R., Dal Fovo, A., Paolantoni, M., Grazia, C., Romani, A., Michelin, A., Andraud C., Tournié, A. \& Dik, J. (2018). Interpreting technical evidence from spectral imaging of paintings by Édouard Manet in the Courtauld Gallery. X-Ray Spectrometry, 1-11.

Armesto-González, J., Riveiro-Rodríguez, B., GonzálezAguilera, D. and Rivas-Brea, M.T., 2010. Terrestrial laser scanning intensity data applied to damage detection for historical buildings. Journal of Archaeological Science, 37(12), 30373047.

Bastonero, P., Donadio, E., Chiabrando, F., and Spanò, A., 2014. Fusion of 3D models derived from TLS and image-based 
techniques for $\mathrm{CH}$ enhanced documentation, ISPRS Ann. Photogramm. Remote Sens. Spatial Inf. Sci., II-5, 73-80.

Bornik, A., Wallner, M., Hinterleitner, A., Verhoeven, G. and Neubauer, W., 2018. Integrated Volume Visualisation of Archaeological Ground Penetrating Radar Data. In 16th Eurographics Workshop on Graphics and Cultural Heritage (GCH 2018), 231-234. The Eurographics Association.

Borrmann, D., Elseberg, J. and Nüchter, A., 2013. Thermal 3D mapping of building façades. In Intelligent Autonomous Systems, 12, 173-182. Springer.

Barone, P. and Ferrara, C., 2018. Non-Invasive Moisture Detection for the Preservation of Cultural Heritage. Heritage, 1(1), 163-170.

Binda, L., Saisi, A. and Tiraboschi, C., 2000. Investigation procedures for the diagnosis of historic masonries. Construction and Building Materials, 14(4), 199-233.

Brumana, R., Oreni, D., Van Hecke, L., Barazzetti, L., Previtali, M., Roncoroni, F. and Valente, R., 2013. Combined geometric and thermal analysis from UAV platforms for archaeological heritage documentation. ISPRS Annals of the Photogrammetry, Remote Sensing and Spatial Information Sciences, 2, 49-54.

Brusco, N., Capeleto, S., Fedel, M., Paviotti, A., Poletto, L., Cortelazzo, G.M. and Tondello, G., 2006. A system for 3D modeling frescoed historical buildings with multispectral texture information. Machine Vision and Applications, 17(6), 373-393.

Cabrelles, M., Galcerá, S., Navarro, S., Lerma, J.L., Akasheh, T. and Haddad, N., 2009, October. Integration of 3D laser scanning, photogrammetry and thermography to record architectural monuments. In Proc. of the 22nd Int. CIPA Symposium, 6-11.

Calia, A., Sileo, M. and Leucci, G., 2012. The assessment of ultrasonic tests as a tool for qualification and diagnostic study of traditional highly porous and soft stone materials used in the built heritage of the past. In EGU General Assembly Conference Abstracts, 14, 9860.

Caliri, C. (2017). A mobile xrf scanner for a real-time elemental imaging of painted artworks. PhD Thesis. University of Catania, INFN - LABORATORI NAZIONALI DEL SUD.

Chane, C., Schütze, R., Boochs, F. and Marzani, F., 2013. Registration of 3D and multispectral data for the study of cultural heritage surfaces. Sensors, 13(1), 1004-1020.

Cho, Y.K., Ham, Y. and Golpavar-Fard, M., 2015. 3D as-is building energy modeling and diagnostics: A review of the stateof-the-art. Advanced Engineering Informatics, 29(2), 184-195.

Costanzo, A., Minasi, M., Casula, G., Musacchio, M. and Buongiorno, M., 2015. Combined use of terrestrial laser scanning and IR thermography applied to a historical building. Sensors, 15(1), 194-213.

Del Pozo, S., Sánchez-Aparicio, L.J., Rodríguez-Gonzálvez, P., Herrero-Pascual, J., Muñoz-Nieto, A., González-Aguilera, D. and Hernández-López, D., 2016. Multispectral imaging: Fundamentals, principles and methods of damage assessment in constructions. Non-Destructive Techniques for the Evaluation of Structures and Infrastructures, 11, 139-166. CRC Press/Balkema.
Erenoglu, R.C., Akcay, O. and Erenoglu, O., 2017. An UASassisted multi-sensor approach for 3D modeling and reconstruction of cultural heritage site. Journal of cultural heritage, 26, 79-90.

Fais, S., Casula, G., Cuccuru, F., Ligas, P. and Bianchi, M.G., 2018. An innovative methodology for the non-destructive diagnosis of architectural elements of ancient historical buildings. Scientific reports, 8(1), 4334-4344.

Fais, S., Cuccuru, F., Ligas, P., Casula, G. and Bianchi, M.G., 2017. Integrated ultrasonic, laser scanning and petrographical characterisation of carbonate building materials on an architectural structure of a historic building. Bulletin of Engineering Geology and the Environment, 76(1), 71-84.

Fell, V., Mould, Q. and White, R., 2006. Guidelines on the Xradiography of Archaeological Metalwork. English Heritage. Ferrara, C. and Barone, P.M., 2015. Detecting moisture damage in archaeology and cultural heritage sites using the GPR technique: a brief introduction. International Journal of Archaeology, 3(1-1), 57-61.

Fryskowska, A., Kedzierski, M., Walczykowski, P., Wierzbicki, D., Delis, P. and Lada, A., 2017. Effective detection of subsurface archeological features from laser scanning point clouds and imagery data. International Archives of the Photogrammetry, Remote Sensing \& Spatial Information Sciences, XLII-2/W5, 245-251.

Georgopoulos, A., Lambrou, E., Pantazis, G., Agrafiotis, P., Papadaki, A., Kotoula, L., Lampropoulos, K., Delegou, E., Apostolopoulou, M., Alexakis, M. and Moropoulou, A., 2017. Merging geometric documentation with materials characterization and analysis of the history of the Holy Aedicule in the Church of the Holy Sepulchre in Jerusalem. International Archives of the Photogrammetry, Remote Sensing \& Spatial Information Sciences, XLII-5/W1, 487-494.

Georgopoulos, A., Oikonomou, C., Adamopoulos, E. and Stathopoulou E. K., 2016. Evaluating Unmanned Aerial Platforms for Cultural Heritage Large Scale Mapping. Int. Arch. Photogramm. Remote Sens. Spatial Inf. Sci., XLI-B5, 355-365.

Grifoni, E., Legnaioli, S., Lorenzetti, G., Pagnotta, S. and Palleschi, V., 2017. Image based recording of three-dimensional profiles of paint layers at different wavelengths. Eur. J. Sci. Theol., 13, 127-134.

Grifoni, E., Legnaioli, S., Nieri, P., Campanella, B., Lorenzetti, G., Pagnotta, S., Poggialini, F. and Palleschi, V., 2018. Construction and comparison of 3D multi-source multi-band models for cultural heritage applications. Journal of Cultural Heritage, 34, 261-267.

Hersak, D., 2013. Beyond the Naked Eye: Ethnography Screened through the Scientific Lens. Critical Interventions, 7(1), 95-104.

Hoegner, L. and Stilla, U., 2018. Mobile thermal mapping for matching of infrared images with 3D building models and 3D point clouds. Quantitative InfraRed Thermography Journal, 15(2), 252-270.

ICOMOS, 1990. Charter for the protection and management of the Archaeological Heritage.

ICOMOS, 2000. Krakow Charter 2000: Principles for conservation and restoration of built Heritage. 
Kadioglu, S., 2010. Definition of Buried Archaeological Remains with a New 3D Visualiza-tion Technique of Ground Penetrating Radar Data Set in Temple Augustus in An-kara, Turkey. Near Surface Geophysics, 8(5), 397-406.

Kedzierski, M., Walczykowski, P., Wojtkowska, M. and Fryskowska, A., 2017. Integration of Point Clouds and Images Acquired from a Low-Cost NIR Camera Sensor for Cultural Heritage Purposes. Int. Arch. Photogramm. Remote Sens. Spatial Inf. Sci., XLII-2/W5, 407-414.

Lagüela, S., Díaz-Vilariño, L., Roca, D. and Filgueira, A., 2016. Thermographic 3D Modeling of Existing Constructions. NonDestructive Techniques for the Evaluation of Structures and Infrastructure, 11, 233-252. CRC Press/Balkema.

Leckebusch, J., 2003. Ground-penetrating radar: a modern threedimensional prospection method. Archaeological prospection, 10(4), 213-240.

Lerones, P.M., Vélez, D.O., Rojo, F.G., Gómez-García-Bermejo, J. and Casanova, E.Z., 2016. Moisture detection in heritage buildings by 3D laser scanning. Studies in Conservation, 61(sup1), 46-54.

Leucci, G., 2017. Seismic and Sonic Applications on Artifacts and Historical Buildings. In Sensing the Past, 153-173. Springer.

Leucci, G., Masini, N., Persico, R. and Soldovieri, F., 2011. GPR and sonic tomography for structural restoration: the case of the cathedral of Tricarico. Journal of Geophysics and Engineering, 8(3), S76-S92.

Lin, D., Jarzabek-Rychard, M., Schneider, D. and Maas, H.G., 2018. Thermal texture selection and correction for building façade inspection based on thermal radiant characteristics. International Archives of the Photogrammetry, Remote Sensing \& Spatial Information Sciences, 42(2), 585-591.

Lo Giudice, A., Corsi, J., Cotto, G., Mila, G., Re, A., Ricci, C., Sacchi, R., Visca, L., Zamprotta, L., Pastrone, N., Albertin, F., Brancaccio, R., Dughera, G., Mereu, P., Staiano, A., Nervo, M., Buscaglia, P., Giovagnoli, A. and Grassi, N. 2017. A new digital radiography system for paintings on canvas and on wooden panels of large dimensions. In the Proceedings of 2017 IEEE I2MTC Conference.

Mannes, D., Schmid, F., Frey, J., Schmidt-Ott, K. and Lehmann, E., 2015. Combined Neutron and X-ray imaging for non-invasive investigations of cultural heritage objects. Physics Procedia, 69 , 653-660.

Marecos, V., Santos-Assunção, S., Fontul, S. and Pérez-Gracia, V., 2016. Geophysics: Fundamentals and Applications in Structures and Infrastructure. Non-Destructive Techniques for the Evaluation of Structures and Infrastructure, 11, 105-134. CRC Press/Balkema.

Martinho, E. and Dionísio, A., 2014. Main geophysical techniques used for non-destructive evaluation in cultural built heritage: a review. Journal of Geophysics and Engineering, 11(5), 053001-053015.

Martinho, E., Dionisio, A., and Mendes, M., 2017. Simulation of a Portuguese limestone masonry structure submitted to fire: 3D Ultrasonic Tomography approach. International Journal of Conservation Science 8(4), 565-580.
Merchán, P., Merchán, M.J., Salamanca, S. and Adán, A., 2018. Application of Multisensory Technology for Resolution of Problems in the Field of Research and Preservation of Cultural Heritage. Advances in Digital Cultural Heritage, 32-47. Springer

Mesquita, E., Martini, R., Alves, A., Antunes, P. and Varum, H., 2018. Non-destructive characterization of ancient clay brick walls by indirect ultrasonic measurements. Journal of Building Engineering, 19, 172-180.

Morigi, M.P., Casali, F., Bettuzzi, M., Brancaccio, R. and d'Errico, V., 2010. Application of X-ray computed tomography to cultural heritage diagnostics. Applied Physics A, 100(3), 653661.

Moropoulou, A. and Labropoulos, K., 2015. Non-destructive testing for assessing structural damage and interventions effectiveness for built cultural heritage protection. In Handbook of Research on Seismic Assessment and Rehabilitation of Historic Structures, 448-499. IGI Global.

Moropoulou, A., Delegou, E.T., Avdelidis, N.P., and Athanasiadou, A., 2005a. Integrated diagnostics using advanced in situ measuring technology. In Proceedings of the 10th international conference on durability of building materials and components, Lyon, 1116-1123.

Nocerino, E., Rieke-Zapp, D.H., Trinkl, E., Rosenbauer, R., Farella, E.M., Morabito, D. and Remondino, F., 2018. Mapping VIS and UVL Imagery on 3D Geometry for Non-Invasive, NonContact Analysis of a Vase. Int. Arch. Photogramm. Remote Sens. Spatial Inf. Sci., XLII-2, 773-780.

Novo, A., Sala, R., Morelli, G., Leckebusch, J. and Tremoleda Trilla, J., 2011, September. Full wave-field recording: STREAM $\mathrm{X}$ at Empuries (Girona, Spain). In 9th International conference on archaeological prospection, 213-217.

Nuzzo, L., Leucci, G., Negri, S., Carrozzo, M.T. and Quarta, T., 2002. Application of 3D visualization techniques in the analysis of GPR data for archaeology. Annals of Geophysics, 45(2), 321337.

O'Connor, S. and Brooks, M., 2007. X-radiography of textiles, dress and related objects. Routledge.

Pamplona, M., Ahmad, A., Simon, S., Abel, E. and Theissen, A., 2012, October. Ultrasonic pulse velocity: A tool for the condition assessment of outdoor marble sculptures. In Proceedings of 12th International Congress on Deterioration and Conservation of Stone. 22-26.

Peccenini, E., Albertin, F., Bettuzzi, M., Brancaccio, R., Casali, F., Morigi, M.P. and Petrucci, F., 2014. Advanced imaging systems for diagnostic investigations applied to Cultural Heritage. In Journal of Physics: The Conference Series, 566(1), 012022. IOP Publishing.

Pelagotti, A., Del Mastio, A., Uccheddu, F. and Remondino, F., 2009, August. Automated multispectral texture mapping of 3D models. In Proc. of the 17th European Signal Processing Conference (EUSIPCO 2009), 1215-1219. IEEE.

Pérez-Gracia, V., Caselles, J.O., Clapes, J., Osorio, R., Martínez, G. and Canas, J.A., 2009. Integrated near-surface geophysical survey of the Cathedral of Mallorca. Journal of Archaeological Science, 36(7), 1289-1299. 
Pérez-Gracia, V., Caselles, J.O., Clapés, J., Martinez, G. and Osorio, R., 2013. Non-destructive analysis in cultural heritage buildings: Evaluating the Mallorca cathedral supporting structures. NDT \& E International, 59, 40-47.

Pitzalis, D., Cignoni, P., Menu, M. and Aitken, G., 2008. 3D enhanced model from multiple data sources for the analysis of the Cylinder seal of Ibni-Sharrum. In VAST 2008: The 9th International Symposium on Virtual Reality, Archaeology, and Cultural Heritage, 79-84. Eurographics Association.

Re, A., Albertin, F., Avataneo, C., Brancaccio, R., Corsi, J., Cotto, G., De Blasi, S., Dughera, G., Durisi, E., Ferrarese, W. and Giovagnoli, A., 2014. X-ray tomography of large wooden artworks: the case study of" Doppio corpo" by Pietro Piffetti. Heritage Science, 2: 19.

Re, A., Corsi, J., Demmelbauer, M., Martini, M., Mila, G. and Ricci, C., 2015. X-ray tomography of a soil block: a useful tool for the restoration of archeological finds. Heritage Science, 3: 4.

Re, A., Lo Giudice, A., Nervo, M., Buscaglia, P., Luciani, P., Borla, M. and Greco, C., 2016. The importance of tomography studying wooden artefacts: a comparison with radiography in the case of a coffin lid from Ancient Egypt. Internation Jourval of Conservation Science 7(S2), 939-944.

Remondino, F., Pelagotti, A., Del Mastio, A. and Uccheddu, F., 2009, July. Novel data registration techniques for art diagnostics and $3 \mathrm{~d}$ heritage visualization. In Proc. of the 9th Conference on Optical 3D Measurement Techniques.

Remondino, F. and Ramos, M. M., 2015. Data Fusion in Cultural Heritage - A Review. The Int. Arch. Photogramm. Remote Sens. Spatial Inf. Sci., XL-5/W7, 359-363.

Rizzi, A., Voltolini, F., Girardi, S., Gonzo, L. and Remondino, F., 2007. Digital preservation, documentation and analysis of paintings, monuments and large cultural heritage with infrared technology, digital cameras and range sensors. International Archives of the Photogrammetry, Remote Sensing and Spatial Information Sciences, 36(Part5/C53), 631-636.

Riveiro, B., Lourenço, P.B., Oliveira, D.V., González-Jorge, H. and Arias, P., 2016. Automatic morphologic analysis of quasiperiodic masonry walls from LiDAR. Computer-Aided Civil and Infrastructure Engineering, 31(4), 305-319.

Sambuelli, L., Bohm, G., Capizzi, P., Cardarelli, E. and Cosentino, P., 2011. Comparison between GPR measurements and ultrasonic tomography with different inversion algorithms: an application to the base of an ancient Egyptian sculpture. Journal of Geophysics and Engineering, 8(3), S106-S116.

Sánchez-Aparicio, L.J., Del Pozo, S., Ramos, L.F., Arce, A. and Fernandes, F.M., 2018. Heritage site preservation with combined radiometric and geometric analysis of TLS data. Automation in Construction, 85, 24-39.

Santos-Assunçao, S., Perez-Gracia, V., Caselles, O., Clapes, J. and Salinas, V., 2014. Assessment of complex masonry structures with GPR compared to other non-destructive testing studies. Remote Sensing, 6(9), 8220-8237.

Schreiner, M., Frühmann, B., Jembrih-Simbürger, D. and Linke, R., 2004. X-rays in art and archaeology: an overview. Powder Diffraction, 19(1), 3-11.
Scopigno, R., Callieri, M., Cignoni, P., Corsini, M., Dellepiane, M., Ponchio, F. and Ranzuglia, G., 2011. 3D models for cultural heritage: beyond plain visualization. Computer, 7, 48-55.

Seccaroni, C., Aresi, N., Frizzi, T., Anselmi, C., \& Sgamellotti, A. (2018). Raphael's workshop at Villa Farnesina in Rome: the frescoed vault of Cupid and Psyche investigated by macro-X-ray fluorescence scanning. Rendiconti Lincei. Scienze Fisiche $e$ Naturali, 29(3), 499-510.

Simon, C., Schütze, R., Boochs, F. and Marzani, F.S., 2012. Asserting the precise position of $3 \mathrm{D}$ and multispectral acquisition systems for multisensor registration applied to cultural heritage analysis. In International Conference on Multimedia Modeling, 597-608. Springer.

Sledz, A., Unger, J. and Heipke, C., 2018. Thermal IR imaging: Image quality and orthophoto generation. International Archives of the Photogrammetry, Remote Sensing and Spatial Information Sciences-ISPRS Archives 42(1), 413-420.

Solla, M., Lorenzo, H. and Pérez-Gracia, V., 2016. Ground Penetrating Radar: Fundamentals, Methodologies and Applications in Structures and Infrastructure. In Non-Destructive Techniques for the Evaluation of Structures and Infrastructure, 11, 135-158. CRC Press/Balkema.

Trinks, I., Wallner, M., Kucera, M., Verhoeven, G., Valdelomar, J.T., Löcker, K., Nau, E., Sevara, C., Aldrian, L., Neubauer, E. and Klein, M., 2017. Documenting bronze age Akrotiri on Thera using laser scanning, image-based modelling and geophysical prospection. The Int. Archives of Photogrammetry, Remote Sensing and Spatial Information Sciences, XLII-2/W3, 631-638.

Verhoeven, G., 2018. The encyclopedia of Archaeological Sciences. John Wiley \& Sons.

Webb, E.K., Robson, S., MacDonald, L., Garside, D. and Evans, R., 2018, May. Spectral and 3D cultural heritage documentation using a modified camera. The Int. Arch. Photogramm. Remote Sens. Spatial Inf. Sci., XLII-2, 1183-1190.

Yalçiner, C.Ç., Bano, M., Kadioglu, M., Karabacak, V., Meghraoui, M. and Altunel, E., 2009. New temple discovery at the archaeological site of Nysa (western Turkey) using GPR method. Journal of Archaeological Science, 36(8), 1680-1689.

Zhang, X., Blaas, J., Botha, C., Reischig, P., Bravin, A. and Dik, J., 2012. Process for the 3D virtual reconstruction of a microcultural heritage artifact obtained by synchrotron radiation CT technology using open source and free software. Journal of Cultural Heritage, 13(2), 221-225.

Zhao, W., Forte, E., Pipan, M. and Tian, G., 2013. Ground penetrating radar (GPR) attribute analysis for archaeological prospection. Journal of Applied Geophysics, 97, 107-117.

Zielińska, M. and Rucka, M., 2018. Non-Destructive Assessment of Masonry Pillars using Ultrasonic Tomography. Materials, 11(12), p.2543-2558. 